\title{
A Chest Compression Quality Evaluation Using Mechanical Chest Compressions under Different Working Situations in the Ambulance
}

\author{
Pär Lindblad1, Annika Åström Victorén1, Christer Axelsson², Bjarne Madsen Härdig3* \\ ${ }^{1}$ Emergency Department, Värnamo County Hospital, Värnamo, Sweden \\ ${ }^{2}$ School of Health Sciences, Borås University, Borås, Sweden \\ ${ }^{3}$ Physio-Control Sweden/Jolife AB, Ideon Science Park, Lund, Sweden \\ Email: par.lindblad@lj.se, annika.astrom.victoren@lj.se, christer.axelsson@hb.se, \\ "bjarne.madsen.hardig@physio-control.com
}

Received 15 January 2015; accepted 3 August 2015; published 6 August 2015

Copyright (C) 2015 by authors and Scientific Research Publishing Inc.

This work is licensed under the Creative Commons Attribution International License (CC BY).

http://creativecommons.org/licenses/by/4.0/

(c) (i) Open Access

\begin{abstract}
Objectives: The aim of this study was to analyze the quality of chest compressions in different working situations pertaining to ambulance crews using either standard chest compressions (S-CC) or LUCAS mechanical chest compressions (L-CC) in a manikin setting. Participants and Methods: Cardiopulmonary resuscitation (CPR) was performed using a compression to ventilation ratio of 30:2 with both S-CC and L-CC. Quality parameters were collected using a modified manikin enabling impedance measurements. The evaluation was performed in two manikin scenarios: Scenario 1 evaluated ten minutes of CPR on the ground and Scenario 2 assessed six minutes of CPR in different settings relevant to work in the ambulance. Quality parameters compared were: time to apply LUCAS, hands-off fraction, number of correct chest compressions and the rate of compressions. Results: In Scenario 1 the hands-off fraction was higher when S-CC was performed (S-CC group $29 \%$ vs. $L-C C 16 \%, P=0.003$ ). We found a higher number of chest compressions (S-CC = 913 vs. $\mathrm{L}-\mathrm{CC}=831, \mathrm{P}=0.0049)$ and a higher rate of chest compressions $(S-C C=118$ vs. $\mathrm{L}-\mathrm{CC}=99, \mathrm{P}<$ $0.0001)$ in the S-CC group. In Scenario 2 we noted a higher hands-off fraction for S-CC (39\% vs. $\mathrm{L}-\mathrm{CC}=19 \%, \mathrm{P}=\mathbf{0 . 0 0 3})$, but a higher number of compressions given during $\mathrm{S}$-CC $((\mathrm{n}=\mathbf{5 0 4}) \mathrm{vs}$. $\mathrm{L}$-CC $(n=396) P=0.0002)$. Conclusion: Mechanical chest compression with the LUCAS $2^{\mathrm{TM}}$ device enables ambulance personnel to provide high quality chest compression even while transporting the patient.
\end{abstract}

${ }^{*}$ Corresponding author.

How to cite this paper: Lindblad, P., Victorén, A.Å., Axelsson, C. and Härdig, B.M. (2015) A Chest Compression Quality Evaluation Using Mechanical Chest Compressions under Different Working Situations in the Ambulance. International Journal of Clinical Medicine, 6, 530-537. http://dx.doi.org/10.4236/ijcm.2015.68071 


\section{Keywords}

\section{Cardiac Arrest, Mechanical Chest Compression, External Chest Compressions, LUCAS CPR, Resuscitation}

\section{Introduction}

In recent cardiopulmonary resuscitation (CPR) guidelines, there has been increased focus on the quality and continuity of chest compression [1] [2]. But ambulance personnel must perform cardiopulmonary resuscitation (CPR) in many different situations that may influence both the quality and continuity. Earlier experimental work [3] has shown that pauses in chest compression have a negative impact on coronary and cerebral flow and thus may decrease the likelihood of both return of spontaneous circulation (ROSC) and survival [4]. One possible way of improving chest compressions quality in the ambulance setting may be the implementation of mechanical chest compressions devices (L-CC). Previous experimental and human studies have shown that these devices improve coronary and cerebral flow parameters compared to standard chest compressions(S-CC) [5]-[7]. When evaluating quality parameters from those studies, it is evident that attaining S-CC quality in the ambulance setting is difficult [8]-[10]. Even with repeated training, high quality S-CC is hard to achieve [11]-[14]. One of the major reasons is personnel fatigue, which impairs quality during S-CC [15]. Study results are sometimes inconsistent in that some studies report quality impairment after a few minutes while other studies show adequate quality S-CC for 10 minutes [13]-[16]. This may be due to the inherent variability of the S-CC technique. Previous studies have shown the usefulness of the information obtained from impedance measurements, when evaluating the quality of standard S-CC and L-CC [17]-[20]. Impedance measurements make it possible to evaluate chest compression pauses, frequency, ventilation, defibrillation pauses and, depending on the equipment used, even depth and recoil [20]. The aim of our current study was to evaluate the effects on chest compression quality between L-CC and S-CC when CPR is performed by ambulance personnel in a manikin setting using a chest compression and ventilation ratio of 30 compressions with a pause for two ventilations (30:2). This ratio is chosen because, over time, endotracheal intubation has become less frequent in the ambulance service [21].

\section{Material and Methods}

\subsection{Study Design}

This study complies with current Swedish laws for clinical research and was performed at the ambulance organization at the Emergency Department, Värnamo County Hospital, Sweden. To enroll participants for this study, the investigator (Pär Lindblad) recruited participants in a randomized manner from those who had been trained to use the LUCAS device (Physio-Control Sweden/Jolife AB, Lund, Sweden). The majority of ambulance personnel volunteered outside of working hours and they were neither paid nor given any financial incentive to participate in the study. Participants had received advanced life support (ALS) training within three month of starting the study. The LUCAS $2^{\mathrm{TM}}$ device training was done six months prior to the study according to company recommendations. All participants were allowed to test the manikin to make sure that they could reach the expected depth. The CPR quality parameters were collected using CODE-STAT 8.0 from Life Pack 12 defibrillators (Physio-Control Inc., Redmond, USA).

One ALS Skillmaster 4000 (Laerdal, Stavanger, Norway) was modified with two cords placed at a depth of $4.5 \mathrm{~cm}$ inside the manikin, which is the average depth according to the resuscitation guidelines of 2005 . This allowed impedance recordings to be taken when the compression exceeded this depth. These cords were connected to the electrodes on the manikin and then connected to the defibrillator pad cable which registered impedance wave forms (Figure 1). The manikin was adjusted to avoid deflection of the back since this has been shown to affect the accuracy of depth measurements [22].

In Scenario 1, the manikin was stationary on the floor, where 10 minutes of CPR was performed. In Scenario 2, the participants started with two minutes of CPR on the floor, then moved the manikin over to the stretcher (AllfaFernoNorden AB, Trollhättan, Sweden) with a fixed height of $70 \mathrm{~cm}$ ) and performed an additional four 


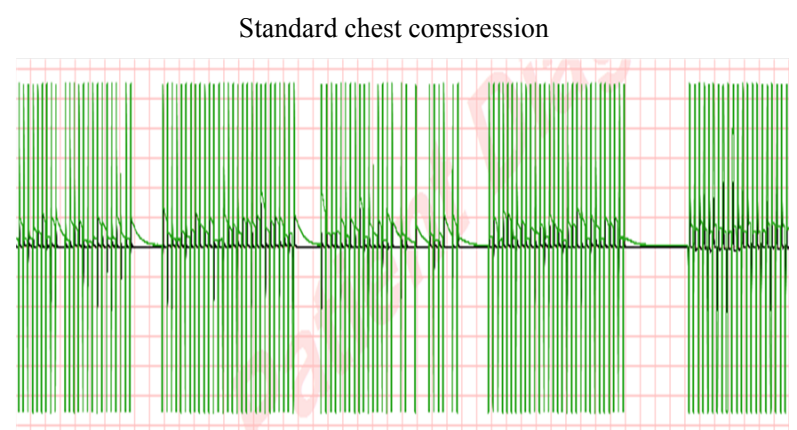

Mechanical chest compression

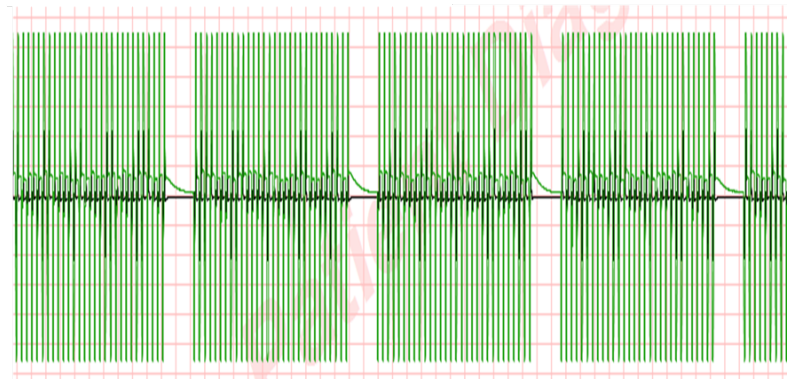

Figure 1. The figure shows a typical example of the impedance measurements using the two chest compression techniques performed in the manikin evaluation.

minutes of CPR, two minutes outside and two minutes inside the ambulance, to simulate a situation where the patient was being transported. The ambulance did not move during Scenario 2. Ambulance personnel worked in pairs in both scenarios (Figure 2), this being the routine in the ambulance organization and therefore used for this study. In the S-CC group, participants followed the recommendation to change chest compression provider every two minutes. In both groups, pauses in chest compressions were made when loading the manikin onto the stretcher and into the ambulance; otherwise, instructions were given to keep the pauses to a minimum. Both scenarios were performed using CPR in the 30:2 ratio and complying with recommendations regarding depth and frequency from the resuscitation guidelines of 2005 , since these were being used clinically during the study period. The following quality parameters were evaluated in both scenarios:

1) Time interval to apply LUCAS (seconds);

2) Hands-off fraction (\% of time);

3) Number of correct compressions (n);

4) Chest compression rate (compressions/minute).

\subsection{Statistics}

All data are presented as median (min-max). The Mann-Whitney U-test was used for statistical comparison and a P-value $<0.05$ was considered significant.

\section{Results}

\subsection{Scenario 1}

The CPR quality parameters were evaluated for 10 pairs of randomly selected ambulance personnel. The time interval to apply LUCAS was 23 seconds $(12-32)$. The total hands-off fraction was higher when S-CC was performed: $29 \%(17 \%-32 \%)$ vs. L-CC 16\% (16\% - 44\%), $\mathrm{P}=0.0003$ (Figure 3). The total number of compressions exceeding $4.5 \mathrm{~cm}$ was higher in the $\mathrm{S}-\mathrm{CC}$ group $(\mathrm{S}-\mathrm{CC}=913(779-963)$ vs. L-CC $=831$ (794 - 846$)$, $\mathrm{P}<0.0001)$. The compression rate was higher when S-CC 118 (97 - 125) was performed compared to L-CC 99 (99 - 100), $\mathrm{P}<0.0001$. 
Two and ten minutes on the floor

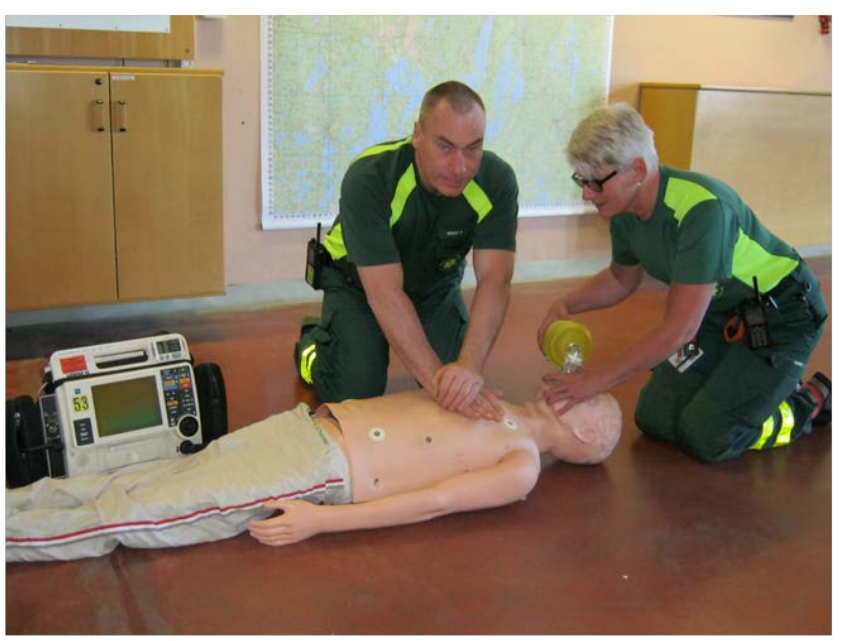

Two minutes on the stretcher

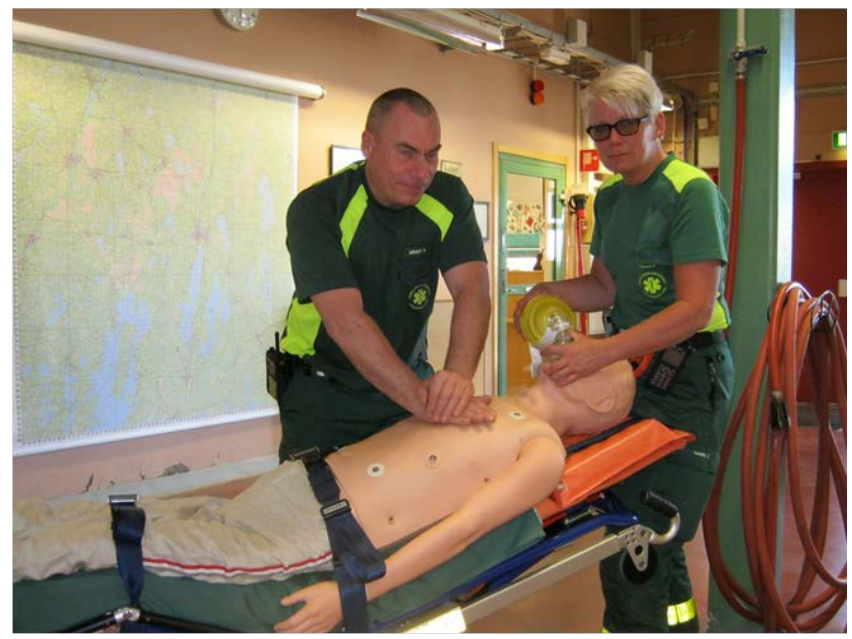

Two minutes in the ambulance

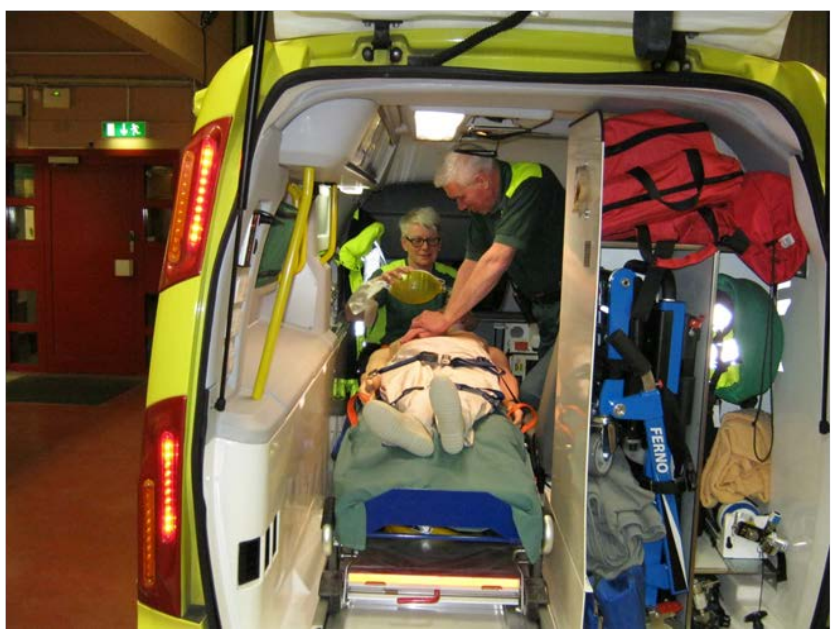

Figure 2. The different manikin scenarios used in the study. These pictures show the three different scenario settings when standard chest compression is performed, the manikin and the equipment used. 


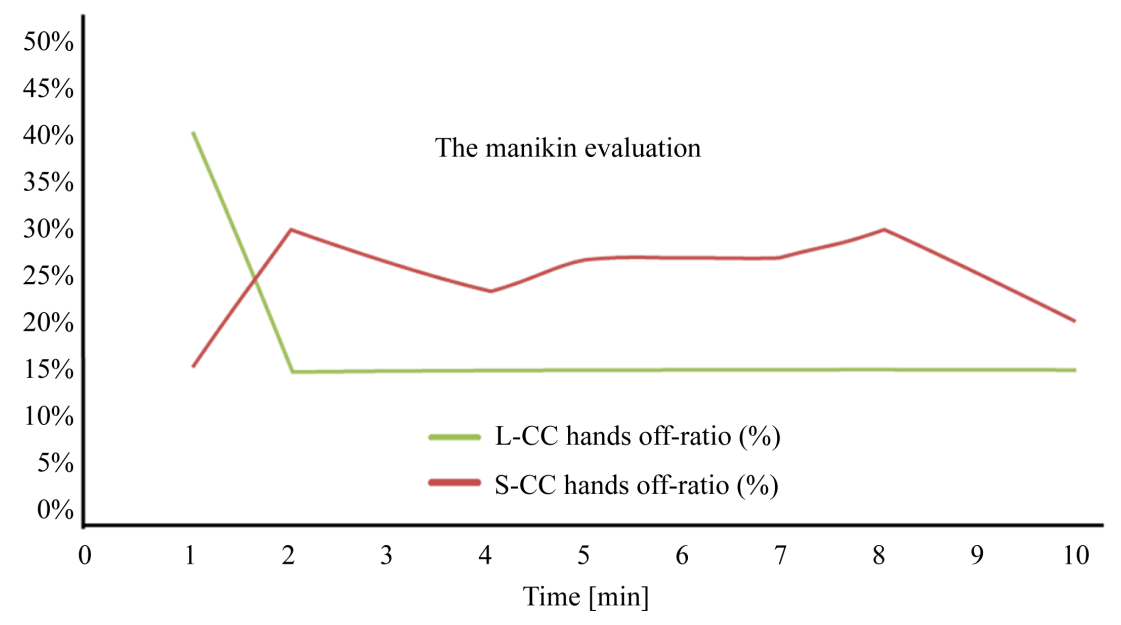

Figure 3. Median chest compressions ratio (\%) during 10 minutes of standard chest compression (S-CC) and LUCAS mechanical chest compression (L-CC) in Scenario 1. This includes pauses in chest compressions for LUCAS application and ventilation.

\subsection{Scenario 2}

Seventeen pairs of randomly selected ambulance personnel were evaluated in this scenario. The time to apply LUCAS in this setting was 11 seconds $(8-30)$. During the first two minutes on the floor, there was a higher chest compression rate noted when S-CC was performed (111 (89 - 118)) compared to L-CC (99 (99 - 99) P < 0.0001). During the two minutes of CPR on the stretcher, a higher hands-off fraction was noted in the S-CC group (58\% vs. $21 \%$ ), and a lower total number of compressions given exceeding $4.5 \mathrm{~cm}$ (S-CC group $=98(0-$ $164)$ vs. L-CC group $=156(146-164), \mathrm{P}<0.0001)$. During the 2 minutes of chest compressions performed in the ambulance, there was a higher hands-off fraction (S-CC group $=22 \%(9 \%-100 \%)$ vs. L-CC group $13 \%$ $(11 \%-13 \%), \mathrm{P}=0.0041)$, and the chest compression rate was higher $(108(91-132)$ vs. $99(99-99), \mathrm{P}=0.002)$ in the S-CC group. When combining the three scenarios (i.e. six minutes of CPR) the hands-off fraction was higher when S-CC was performed ( $39 \%$ vs. L-CC $=19 \%, \mathrm{P}<0.0001)$. The individual variations for both techniques regarding hands-off fraction can be seen in Figure 4.

\section{Discussion}

It was apparent that there are chest compressions quality differences between the two scenarios when using either S-CC or L-CC in working situations faced by ambulance personnel. A high chest compressions rate affected the number of pauses when S-CC was performed in 30:2 and increased the total hands-off fraction compared to when L-CC was used. It has been shown that a low proportion hands-off fraction is important if ROSC is to be achieved [23] [24]. We noted a higher chest compression rate during S-CC compared to guideline recommendations from both 2005 and 2010 [2]. Compared to recommendations in the 2010 guidelines regarding chest compressions rate, only $28 \%$ of the S-CC performed was within the recommendation of $100-120$ compressions per minute.

We also noted various degrees of difficulty when performing chest compressions at a depth of over $4.5 \mathrm{~cm}$ for different ambulance personnel in Scenario 2, i.e. on the stretcher and in the ambulance, when chest compressions were done by S-CC, as shown in a previous study [8]. One reason for lack of chest compression depth when S-CC is performed might be that the participants were poorly trained [25], even though training followed the local recommendations. Another explanation might be that the training environments are seldom relevant to the clinical setting [26]. Yet another explanation could be the individual provider's physical size. In earlier studies, the difference in individual CPR providers' physical size has been shown to affect the ability to perform high quality chest compressions even in children and young adults [27]. In Scenario 2 (Figure 4) we noted a large variation between the teams when they started to move the patient, which is consistent with findings from a previous study [10]. The contribution of psychological stress factors that occur in real clinical cardiac arrest situations [28] is less likely since the participants were informed about the evaluation. There is a risk/benefit 


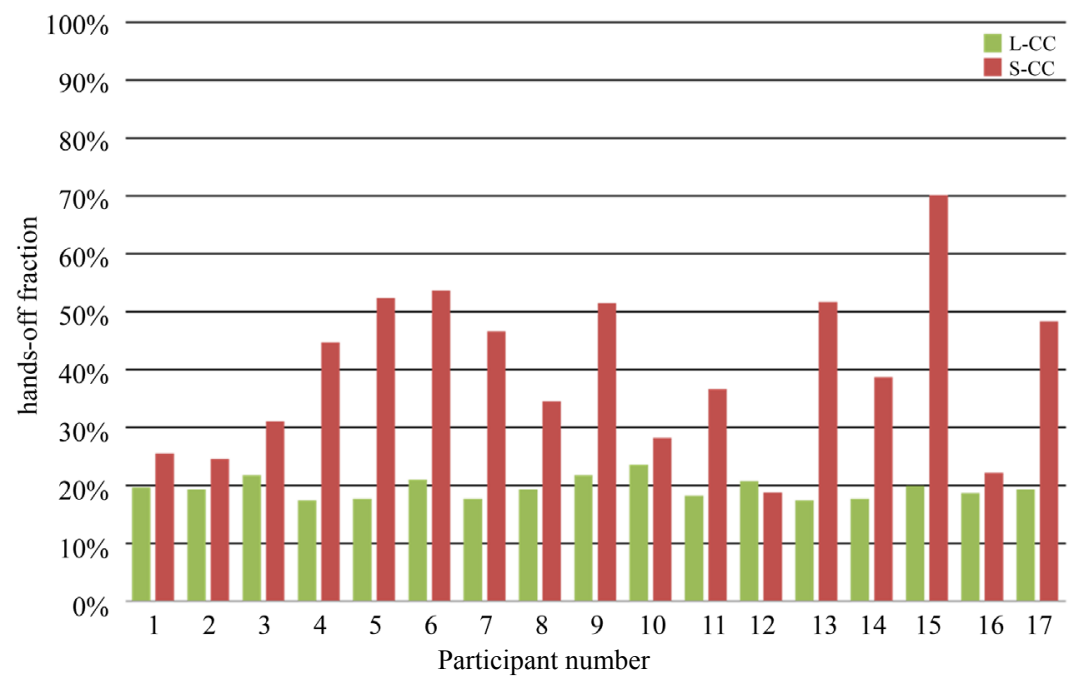

Figure 4. Individual hands-off fraction (\%) during three CPR situations relevant to the clinical ambulance service. The median individual hands-off fraction (\%) during six minutes of CPR using standard chest compression (S-CC) and LUCAS mechanical chest compression (L-CC). This includes pauses in chest compressions for LUCAS application, ventilation, loading onto the stretcher and into the ambulance, as well as incorrect depth (i.e. $<4.5 \mathrm{~cm})$.

consideration when conducting S-CC in the ambulance. Patients may need transportation yet ongoing S-CC is unsafe for the ambulance crew. In this situation it seems reasonable to use L-CC, as a report from Asia and US have suggested [29]. However, it is important to provide high quality S-CC, and having a mechanical chest compression device does not diminish the attention of this required of the personnel. Moreover, individual differences have been seen regarding the application time of the L-CC. Therefore S-CC as the initial treatment before the first defibrillation of VF seems to be the most appropriate strategy [30]. The application time of the L-CC device should be an important consideration when using a L-CC device, because the perceived time taken for the transition between S-CC and L-CC might not reflect the measured time [20]. It is also a matter of training and, if this process is monitored and measured, it is possible to shorten the application time and therefore reduce the hands-off fraction [31]. Chest compressions quality might be the most important factor for the group of patients that do not initially respond to defibrillation and/or do not achieve ROSC [18]. It is not enough simply to go along with current standards, saying, "push hard and push faster" because this will not assure quality CPR [32]. We found that an increased chest compressions rate also increases the number and length of pauses and therefore the total hands-off fraction, which could reduce the chances of achieving ROSC [23]. To perform high quality chest compressions requires a combination of depth, rate and duty cycle, to allow for full recoil and short hands-off fractions [33] [34] and this was best provided by L-CC in the present study.

\section{Limitations}

ALS manikins are made for education and training purposes, not for precise CPR depth measurements. According to the manufacturer, it measures CPR depth with an accuracy of $\pm 15 \%$. The surface beneath the manikin's back has also been shown to affect the reliability of depth measurements [22]. To minimize this effect, the space beneath the manikin's back was filled to minimize deflection from the back of the manikin. We were not able to measure chest recoil in this setting, which also is an important factor for high quality CPR [35]. The number of years of training and the situations in which training is performed varies between different personnel and this could affect the results seen. The use of a metronome would be one way to control the compression rate but this was not used in this study [36].

\section{Conclusion}

Mechanical chest compression with the LUCAS $2^{\mathrm{TM}}$ device enables ambulance personnel to provide high quali- 
ty chest compression even while transporting the patient.

\section{References}

[1] Handley, A.J., Koster, R., Monsieurs, K., Perkins, G.D., Davies, S. and Bossaert, L. (2005) European Resuscitation Council Guidelines for Resuscitation 2005. Section 2. Adult Basic Life Support and Use of Automated External Defibrillators. Resuscitation, 67, S7-S23. http://dx.doi.org/10.1016/j.resuscitation.2005.10.007

[2] Koster, R.W., Baubin, M.A., Bossaert, L.L., Caballero, A., Cassan, P., Castren, M., Granja, C., Handley, A.J., Monsieurs, K.G., Perkins, G.D., et al. (2010) European Resuscitation Council Guidelines for Resuscitation 2010 Section 2. Adult Basic Life Support and Use of Automated External Defibrillators. Resuscitation, 81, 1277-1292. http://dx.doi.org/10.1016/j.resuscitation.2010.08.009

[3] Berg, R.A., Sanders, A.B., Kern, K.B., Hilwig, R.W., Heidenreich, J.W., Porter, M.E. and Ewy, G.A. (2001) Adverse Hemodynamic Effects of Interrupting Chest Compressions for Rescue Breathing During Cardiopulmonary Resuscitation for Ventricular Fibrillation Cardiac Arrest. Circulation, 104, 2465-2470. http://dx.doi.org/10.1161/hc4501.098926

[4] Paradis, N.A., Martin, G.B., Rivers, E.P., Goetting, M.G., Appleton, T.J., Feingold, M. and Nowak, R.M. (1990) Coronary Perfusion Pressure and the Return of Spontaneous Circulation in Human Cardiopulmonary Resuscitation. The Journal of the American Medical Association, 263, 1106-1113. http://dx.doi.org/10.1001/jama.1990.03440080084029

[5] Jiménez, F.C., Padró, P.P., Garciá, Á.S. and Venegas, J.C.R. (2012) Cerebral Blood Flow Measured by Transcranial Doppler Ultrasound during Manual Chest Wall or Automated LUCAS-2 Compressions during Cardiopulmonary Resuscitation. Emergencias, 24, 47-49.

[6] Rubertsson, S. and Karlsten, R. (2005) Increased Cortical Cerebral Blood Flow with LUCAS: A New Device for Mechanical Chest Compressions Compared to Standard External Compressions during Experimental Cardiopulmonary Resuscitation. Resuscitation, 65, 357-363. http://dx.doi.org/10.1016/j.resuscitation.2004.12.006

[7] Wagner, H., Härdig, B.M., Harnek, J., Götberg, M. and Olivecrona, G.K. (2010) Mechanical Chest Compressions Maintain Vital Physiology during Prolonged Resuscitation Efforts in the Cath-Lab. Resuscitation, 81, S61. http://dx.doi.org/10.1016/j.resuscitation.2010.09.252

[8] Olasveengen, T.M., Wik, L. and Steen, P.A. (2008) Quality of Cardiopulmonary Resuscitation before and during Transport in Out-of-Hospital Cardiac Arrest. Resuscitation, 76, 185-190. http://dx.doi.org/10.1016/j.resuscitation.2007.07.001

[9] Putzer, G., Braun, P., Zimmermann, A., Pedross, F., Strapazzon, G., Brugger, H. and Paal, P. (2013) LUCAS Compared to Manual Cardiopulmonary Resuscitation Is More Effective during Helicopter Rescue - A Prospective, Randomized, Cross-Over Manikin Study. American Journal of Emergency Medicine, 31, 384-389. http://dx.doi.org/10.1016/j.ajem.2012.07.018

[10] Roosa, J.R., Vadeboncoeur, T.F., Dommer, P.B., Panchal, A.R., Venuti, M., Smith, G., Silver, A., Mullins, M., Spaite, D. and Bobrow, B.J. (2013) CPR Variability during Ground Ambulance Transport of Patients in Cardiac Arrest. Resuscitation, 84, 592-595. http://dx.doi.org/10.1016/j.resuscitation.2012.07.042

[11] Yang, C.W., Yen, Z.S., McGowan, J.E., Chen, H.C., Chiang, W.C., Mancini, M.E., Soar, J., Lai, M.S. and Ma, M.H.M. (2012) A Systematic Review of Retention of Adult Advanced Life Support Knowledge and Skills in Healthcare Providers. Resuscitation, 83, 1055-1060. http://dx.doi.org/10.1016/j.resuscitation.2012.02.027

[12] Foo, N.P., Chang, J.H., Lin, H.J. and Guo, H.R. (2010) Rescuer Fatigue and Cardiopulmonary Resuscitation Positions: A Randomized Controlled Crossover Trial. Resuscitation, 81, 579-584. http://dx.doi.org/10.1016/j.resuscitation.2010.02.006

[13] Jantti, H., Silfvast, T., Turpeinen, A., Kiviniemi, V. and Uusaro, A. (2009) Influence of Chest Compression Rate Guidance on the Quality of Cardiopulmonary Resuscitation Performed on Manikins. Resuscitation, 80, 453-457. http://dx.doi.org/10.1016/j.resuscitation.2009.01.001

[14] Heidenreich, J.W., Sanders, A.B., Higdon, T.A., Kern, K.B., Berg, R.A. and Ewy, G.A. (2004) Uninterrupted Chest Compression CPR Is Easier to Perform and Remember Than Standard CPR. Resuscitation, 63, 123-130. http://dx.doi.org/10.1016/j.resuscitation.2004.04.011

[15] McDonald, C., Heggie, J., Jones, C., Thorne, C. and Hulme, J. (2012) Assessing Rescuer Fatigue and Resultant CPR Performance under the New 2010 ERC Guidelines. Resuscitation, 83, e34. http://dx.doi.org/10.1016/j.resuscitation.2012.08.085

[16] Bjorshol, C.A., Sunde, K., Myklebust, H., Assmus, J. and Soreide, E. (2011) Decay in Chest Compression Quality Due to Fatigue Is Rare during Prolonged Advanced Life Support in a Manikin Model. Scandinavian Journal of Trauma, Resuscitation and Emergency Medicine, 19, 46. http://dx.doi.org/10.1186/1757-7241-19-46

[17] Stiell, I.G., Brown, S.P., Christenson, J., Cheskes, S., Nichol, G., Powell, J., Bigham, B., Morrison, L.J., Larsen, J., Hess, E., et al. (2012) What Is the Role of Chest Compression Depth during Out-of-Hospital Cardiac Arrest Resuscita- 
tion?. Critical Care Medicine, 40, 1192-1198. http://dx.doi.org/10.1097/CCM.0b013e31823bc8bb

[18] Fried, D.A., Leary, M., Smith, D.A., Sutton, R.M., Niles, D., Herzberg, D.L., Becker, L.B. and Abella, B.S. (2011) The Prevalence of Chest Compression Leaning during In-Hospital Cardiopulmonary Resuscitation. Resuscitation, 82, 10191024. http://dx.doi.org/10.1016/j.resuscitation.2011.02.032

[19] Olasveengen, T.M., Wik, L., Kramer-Johansen, J., Sunde, K., Pytte, M. and Steen, P.A. (2007) Is CPR Quality Improving? A Retrospective Study of Out-of-Hospital Cardiac Arrest. Resuscitation, 75, 260-266. http://dx.doi.org/10.1016/j.resuscitation.2007.04.016

[20] Yost, D., Phillips, R.H., Gonzales, L., Lick, C.J., Satterlee, P., Levy, M., Barger, J., Dodson, P., Poggi, S., Wojcik, K., et al. (2012) Assessment of CPR Interruptions from Transthoracic Impedance during Use of the LUCAS Mechanical Chest Compression System. Resuscitation, 83, 961-965. http://dx.doi.org/10.1016/j.resuscitation.2012.01.019

[21] Herlitz, J. and Coworkers (2011) Nationellt Register för hjärtstopp Årsrapport. http://www.hlr.nu/wp-content/uploads/Hjartstoppsregistret-Arsrapport-2011.pdf

[22] Nilsson, A. and Chapman, F.W. (2012) Technical Factors Weaken the Clinical Relevance of Manikin Measurements of Mechanical Chest Compression Depth. Resuscitation, 83, e97.

[23] Vaillancourt, C., Everson-Stewart, S., Christenson, J., Andrusiek, D., Powell, J., Nichol, G., Cheskes, S., Aufderheide, T.P., Berg, R. and Stiell, I.G. (2011) The Impact of Increased Chest Compression Fraction on Return of Spontaneous Circulation for Out-of-Hospital Cardiac Arrest Patients Not in Ventricular Fibrillation. Resuscitation, 82, 1501-1507. http://dx.doi.org/10.1016/j.resuscitation.2011.07.011

[24] Idris, A.H., Guffey, D., Aufderheide, T.P., Brown, S., Morrison, L.J., Nichols, P., Powell, J., Daya, M., Bigham, B.L., Atkins, D.L., et al. (2012) Relationship between Chest Compression Rates and Outcomes from Cardiac Arrest. Circulation, 125, 3004-3012. http://dx.doi.org/10.1161/CIRCULATIONAHA.111.059535

[25] Oermann, M.H., Kardong-Edgren, S.E. and Odom-Maryon, T. (2011) Effects of Monthly Practice on Nursing Students' CPR Psychomotor Skill Performance. Resuscitation, 82, 447-453. http://dx.doi.org/10.1016/j.resuscitation.2010.11.022

[26] Seethala, R.R., Esposito, E.C. and Abella, B.S. (2010) Approaches to Improving Cardiac Arrest Resuscitation Performance. Current Opinion in Critical Care, 16, 196-202. http://dx.doi.org/10.1097/MCC.0b013e328338c121

[27] Niles, D.E., Nishisaki, A., Sutton, R.M., Nysaether, J., Eilevstjonn, J., Leffelman, J., Maltese, M.R., Arbogast, K.B., Abella, B.S., Helfaer, M.A., et al. (2012) Comparison of Relative and Actual Chest Compression Depths during Cardiac Arrest in Children, Adolescents, and Young Adults. Resuscitation, 83, 320-326. http://dx.doi.org/10.1016/j.resuscitation.2011.10.014

[28] Hunziker, S., Semmer, N.K., Tschan, F., Schuetz, P., Mueller, B. and Marsch, S. (2012) Dynamics and Association of Different Acute Stress Markers with Performance during a Simulated Resuscitation. Resuscitation, 83, 572-578. http://dx.doi.org/10.1016/j.resuscitation.2011.11.013

[29] Hock Ong, M.E., Shin, S.D., Sung, S.S., Tanaka, H., Huei-Ming, M., Song, K.J., et al. (2013) Recommendations on Ambulance Cardiopulmonary Resuscitation in Basic Life Support Systems. Prehospital Emergency Care, 17, 491-500. http://dx.doi.org/10.3109/10903127.2013.818176

[30] O'Connor, R.E. (2010) The Application of Mechanical Devices for CPR: Make the First 5 Minutes the Best 5 Minutes! Annals of Emergency Medicine, 56, 242-243. http://dx.doi.org/10.1016/j.annemergmed.2010.02.028

[31] Are the Benefits of Mechanical CPR Worth the Interruption Time? http://www.jems.com/article/patient-care/are-benefits-mechanical-cpr-worth-interr

[32] Berg, R.A., Hemphill, R., Abella, B.S., Aufderheide, T.P., Cave, D.M., Hazinski, M.F., Lerner, E.B., Rea, T.D., Sayre, M.R. and Swor, R.A. (2010) Part 5: Adult Basic Life Support: 2010 American Heart Association Guidelines for Cardiopulmonary Resuscitation and Emergency Cardiovascular Care. Circulation, 122, S685-S705. http://dx.doi.org/10.1161/CIRCULATIONAHA.110.970939

[33] Aufderheide, T.P., Pirrallo, R.G., Yannopoulos, D., Klein, J.P., von Briesen, C., Sparks, C.W., Deja, K.A., Conrad, C.J., Kitscha, D.J., Provo, T.A. and Lurie, K.G. (2005) Incomplete Chest Wall Decompression: A Clinical Evaluation of CPR Performance by EMS Personnel and Assessment of Alternative Manual Chest Compression-Decompression Techniques. Resuscitation, 64, 353-362. http://dx.doi.org/10.1016/j.resuscitation.2004.10.007

[34] Hostler, D., Rittenberger, J.C., Roth, R. and Callaway, C.W. (2007) Increased Chest Compression to Ventilation Ratio Improves Delivery of CPR. Resuscitation, 74, 446-452. http://dx.doi.org/10.1016/j.resuscitation.2007.01.022

[35] Niles, D.E., Sutton, R.M., Nadkarni, V.M., Glatz, A., Zuercher, M., Maltese, M.R., Eilevstjonn, J., Abella, B.S., Becker, L.B. and Berg, R.A. (2011) Prevalence and Hemodynamic Effects of Leaning during CPR. Resuscitation, 82, S23S26. http://dx.doi.org/10.1016/S0300-9572(11)70147-2

[36] Kern, K.B., Stickney, R.E., Gallison, L. and Smith, R.E. (2010) Metronome Improves Compression and Ventilation Rates during CPR on a Manikin in a Randomized Trial. Resuscitation, 81, 206-210. http://dx.doi.org/10.1016/j.resuscitation.2009.10.015 